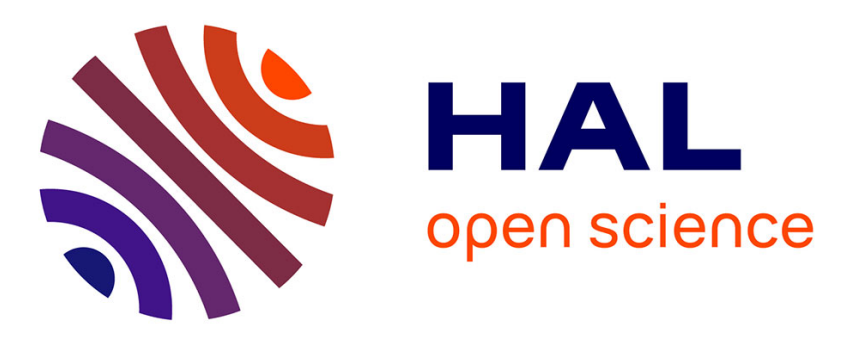

\title{
Iron as a therapeutic target for Parkinson's disease
}

Caroline Moreau, James A. Duce, Olivier Rascol, Jean Christophe Devedjan,

Daniela Berg, David Dexter, Z. Ioav Cabantchik, Ashley I. Bush, David Devos

\section{To cite this version:}

Caroline Moreau, James A. Duce, Olivier Rascol, Jean Christophe Devedjan, Daniela Berg, et al.. Iron as a therapeutic target for Parkinson's disease. Movement Disorders, 2018, Movement Disorders, 33 (4), pp.568-574. 10.1002/mds.27275 . hal-02150661

\section{HAL Id: hal-02150661 https://hal.univ-lille.fr/hal-02150661}

Submitted on 7 Jun 2019

HAL is a multi-disciplinary open access archive for the deposit and dissemination of scientific research documents, whether they are published or not. The documents may come from teaching and research institutions in France or abroad, or from public or private research centers.
L'archive ouverte pluridisciplinaire HAL, est destinée au dépôt et à la diffusion de documents scientifiques de niveau recherche, publiés ou non, émanant des établissements d'enseignement et de recherche français ou étrangers, des laboratoires publics ou privés. 


\section{Iron as a therapeutic target for Parkinson's disease}

\begin{tabular}{|c|c|}
\hline Journal: & Movement Disorders \\
\hline Manuscript ID & MDS-17-0593.R3 \\
\hline Wiley - Manuscript type: & Viewpoint \\
\hline Date Submitted by the Author: & $n / a$ \\
\hline Complete List of Authors: & $\begin{array}{l}\text { Moreau, Caroline; roger salengro hospital, neurology } \\
\text { Duce, James } \\
\text { Rascol, Olivier; Faculty of Medicine Purpan, University UPS of Toulouse III, } \\
\text { Departments of Clinical Pharmacology and Neurosciences - CIC- } \\
\text { 9302/INSERM UMR825 } \\
\text { Devedjian, Jean-Christophe; Faculty of Medicine, Lille University, INSERM } \\
\text { U1171; Lille University, Department of Medical Pharmacology } \\
\text { Berg, Daniela; Christian-Albrechts Universität, Klinik für Neurologie } \\
\text { Dexter, David } \\
\text { Cabantchik, Ioav } \\
\text { Bush, Ashley; Florey Institute of Neuroscience and Mental Health } \\
\text { Devos, David; University of Lille Nord de France, Medical Pharmacology }\end{array}$ \\
\hline Keywords: & $\begin{array}{l}\text { Parkinson's disease - conservative iron chelation - dopamine oxidative } \\
\text { stress - alpha synuclein - ferroptosis }\end{array}$ \\
\hline
\end{tabular}


* Equally contributed

1 Université de Lille, CHU de Lille, INSERM UMRS_1171, Service de Neurologie NS-Park/FCRIN Network LICEND COEN Center Lille, France 2 School of Biomedical Sciences, Faculty of Biological Sciences, University of Leeds, Leeds, West Yorkshire, UK \& Oxidation Biology Unit, The Florey Institute of Neuroscience and Mental Health, The University of Melbourne, Parkville, Victoria, Australia

3 Université de Toulouse, UPS, CHU de Toulouse, INSERM; Centre d'Investigation Clinique CIC1436, Services de Neurologie et de Pharmacologie Clinique, UMR TONIC, NS-Park/FCRIN Network, NeuroToul COEN Center, Toulouse, France

4 University de Lille, CHU de Lille, INSERM UMRS_1171, NS-Park/FCRIN Network LICEND COEN Center Lille, France

5 Department of Neurology, Christian-Albrechts-University of Kiel, Kiel, Germany and HertieInstitute of Clinical Brain Research, Department of Neurodegeneration, Tübingen, Germany 6 Imperial College London London United Kingdom

7 Della Pergola Chair, Alexander Silberman Institute of Life Sciences, Hebrew University, Jerusalem, 91904, Israel

8 Oxidation Biology Unit, The Florey Institute of Neuroscience and Mental Health, The University of Melbourne, Parkville, Victoria, Australia

9 Université de Lille, CHU de Lille, INSERM UMRS_1171, Service de Pharmacologie Clinique et service de Neurologie NS-Park/FCRIN Network LICEND COEN Center Lille, France

Corresponding author: Devos David, MD, $\mathrm{PhD}$

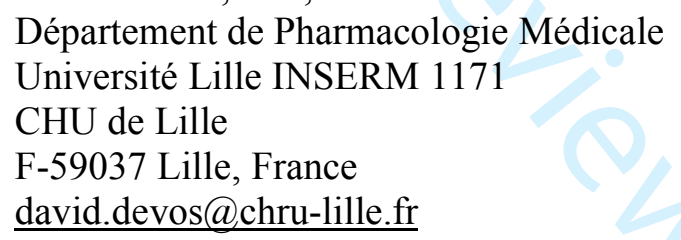

Running title: Iron and Parkinson's disease

Key words: Parkinson's disease - conservative iron chelation - dopamine oxidative stress alpha synuclein - ferroptosis

Title: 52 characters, running title: 29 characters, $1909<2000$ words, 3 Figures, 1 Table, 40 references

Financial disclosure related to research covered in this article: The authors have no financial disclosures to make or potential conflicts of interest to report in relation to this study. The paper is referring to an academic study in progress, with the French NS-Park network, which is funded by a grant from the European Commission Horizon 2020 PHC13 2014-2015 ( $\mathrm{N}^{\circ}$ 633190): "Conservative iron chelation as a disease-modifying strategy in Parkinson's disease: a multicentre, parallel-group, placebo-controlled, randomized clinical trial of deferiprone (FAIR-PARK-II)" Protocol ID: 2015_22; Clinical trial: NCT02655315 http://fairpark2.eu. ApoPharma provided deferiprone and advices on the molecule. 


\section{Introduction}

An urgent need for efficacious disease modifying therapies is required to slow down Parkinson's disease (PD) progression. Iron is required as a cofactor in metabolic processes throughout the body and specifically in tissues of high oxygen consumption, such as the central nervous system. The redox chemistry of iron is critical for neurotransmitter regulation as well as mitochondrial oxidative phosphorylation, nitric oxide metabolism and oxygen transport. ${ }^{1}$ Iron homeostasis involves the orchestration of systemic and cellular networks for the acquisition, internal distribution and utilization of iron. ${ }^{2}$ Disruption of links can lead to abnormal redistribution of iron, causing deleterious consequences (siderosis) either by localized accumulation and/or deficits in specific cellular compartments or tissues. Excessive labile iron in the substantia nigra pars compacta $(\mathrm{SNc})$ has become a pathognomonic hallmark of PD and leads to increased production of noxious reactive oxygen species (ROS), which is also prevalent in PD. Conversely, a deficiency in iron impairs energy production ${ }^{2}$ and can also cause dopaminergic neurodegeneration in mice. ${ }^{3}$ In mammalian models, chelators that scavenge intracellular iron protect against oxidative neuronal damage. However, these strong iron chelation regimens are designed to treat systemic siderosis and are not suitable for PD patients, as iatrogenic iron depletion and anaemia may ensue. Moderate iron chelation modality that conserves systemic iron offers a novel therapeutic strategy for neuroprotection. 


\section{Iron in dopaminergic neurons}

Iron is particularly abundant in $\mathrm{SNc}$ dopaminergic neurons as an integral component of tyrosine hydroxylase (TH)-dependent dopamine synthesis as well as other enzymatic and nonenzymatic reactions associated with dopamine metabolism. ${ }^{4}$ The identification of substantial brain labile non-heme high-spin complexes, which increase with age, ${ }^{5}$ might explain the iron catalytic role in the generation of noxious ROS by Fenton chemistry involving hydrogen peroxide. In part, this results from the oxidative deamination of dopamine by monoamine oxidase and the formation of metastable iron-dopamine complexes that in turn lead to dopamine auto-oxidation and quinone formation.

The sequestration of various potentially toxic products sequestered by neuromelanin confer a distinctive pigmentation upon the SNc. However, as the neuromelanin sanctuary for toxins is lost during $\mathrm{PD},{ }^{4}$ the labile endogenous autooxidation products of dopamine can strongly impair respiration by the mitochondrial complexes I and IV. A high-energy demand, due to autonomous pace-making activity, might also render the SNc more susceptible to imbalances in labile iron levels and ensuing ROS production. ${ }^{6}$

\section{Iron deposits measured in the SNc in PD}

Iron accumulation has been identified in the SNc of post mortem brains of patients ${ }^{1,2,7,11}$ as well as all Parkinsonian animal models. ${ }^{1,2,7-11}$ This has been confirmed in patients by ironsensitive high field MRI ( 3 and 7 Tesla) with a quantitative weighted T2* sequence showing a higher R2* value (Fig. 1). ${ }^{9,12,13}$ Longitudinal studies as well as a meta-analysis have identified a progressive iron accumulation in the $\mathrm{SNc}$ through the course of disease. ${ }^{12,13,14}$ Visual assessment of dorsolateral SN hyperintensity by Susceptibility Weighted Imaging can differentiate PD versus controls ${ }^{15}$ and these observations have been corroborated by reduced transverse relaxation; ${ }^{16}$ another measurement of rate sequence. More recently, a novel MRI approach with Quantitative Susceptibility Mapping (QSM) has demonstrated superior 
sensitivity for mapping changes in non-heme iron levels ${ }^{17,18}$ and a new sequence of magnetization transfer contrast has identified a local neuromelanin density reduction in the SNc. ${ }^{19}$ Transcranial ultrasound that visualizes hyperechogenicity of SNc tissue has also identified increased iron levels relating to alterations in iron metabolism genes. ${ }^{20,21}$

\section{What could be the cellular mechanisms implicated in iron accumulation?}

\section{Impaired iron release}

Ferroportin is depleted in parkinsonian models including intoxication with 1-methyl-4phenyl-1,2,3,6-tetrahydropyridine (MPTP) and 6-hydroxydopamine (6-OHDA). ${ }^{1}$ Depletion of either amyloid precursor protein (APP) or tau function causes neuronal iron retention as well as iron-dependent nigral cell loss, and both proteins are decreased in the $\mathrm{SNc}$ in $\mathrm{PD}^{7,22}$ Cellular iron egress by ferroportin may also be assisted by ceruloplasmin and mice deficient of this enzyme develop deferiprone (DFP) rescuable age-dependent iron elevation and parkinsonism. ${ }^{7}$ In PD patients a low ceruloplasmin activity has been identified in the $\mathrm{SN}$, cerebrospinal fluid (CSF) and serum. ${ }^{1}$ Point mutations in the ceruloplasmin gene also associate with parkinsonism ${ }^{11}$ and $\mathrm{SN}$ hyperechogenicity in $\mathrm{PD}$. $^{7,23}$

\section{Altered iron storage}

The limited capacity of neurons to sequester surplus iron into ferritin molecules ${ }^{1,2}$ is complemented by expressing neuromelanin as an alternative "iron sink". However, such capacities might be exceeded in $\mathrm{PD},{ }^{2}$ potentially leading to increased ferritinimmunoreactivity in microglia in the SN. ${ }^{24}$ Elevated levels of iron loaded ferritin may, over time, contribute to age-related neurodegeneration by acting as a metastable reservoir for iron. $1,2,4$

\section{Increased iron uptake}


Single nucleotide polymorphisms in transferrin (Tf) and its receptor (TfR) identified from PD case-control studies may have a protective role via changes to Tf bound iron transport into the cell. ${ }^{25}$ Lactoferrin and its receptor may also play a similar role. ${ }^{26}$ Finally, iron accumulation in the SNc of patients and MPTP mice correlate with elevation of the iron importer, divalent metal transporter 1 (DMT1). ${ }^{27}$

\section{Is there interplay between iron and $\alpha$-synuclein?}

Iron markedly induces aggregation of $\alpha$-synuclein into intracellular inclusions (i.e. Lewy bodies). ${ }^{28}$ Consistent with iron deposition, QSM measurements follow a pattern with the distributions of $\alpha$-synuclein in PD pathology. ${ }^{17}$ Since the identification that iron can translationally increase protein levels of $\alpha$-synuclein through its promoter region, ${ }^{28}$ more recent evidence has suggested a role for $\alpha$-synuclein in modulating iron homeostasis. Depletion of $\alpha$-synuclein in a functional location impairs the capacity for TfR to import iron and indicates that $\alpha$-synuclein could modulate clatherin-mediated endocytosis. ${ }^{28}$ Neonatal iron-feeding of a transgenic mouse model overexpressing human $\alpha$-synuclein bearing the A53T mutation exacerbates both PD-related motor and non-motor phenotypes. ${ }^{29}$ Accordingly, iron chelation reduces the amount of insoluble $\alpha$-synuclein aggregates ${ }^{29}$ and rescues behavioural deficits ${ }^{30}$ in murine models of genetic PD.

\section{Ferroptosis - a new iron-dependent cell death pathway in PD that may yield further}

\section{therapeutic options}

A new iron dependent cell death pathway that has recently come to light has strong implications in PD neuropathology. Ferroptosis appears to be selectively triggered by an iron dependent mechanism with key features including lipid peroxidation, specific depletion of glutathione peroxidases-4 to alter glutathione protection, mitochondriopathy and distinct 
morphological modifications that are independent from other cell death pathways (e.g. apoptosis, necrosis and autophagy). ${ }^{31,32}$ Inhibition of the xCT cystine/glutamate antiporter during ferroptosis consequentially prevents cystine uptake into the cell and leads to lower levels of glutathione synthesis and increases cellular availability of labile iron to catalyse lipid peroxidation (Fig. 2). ${ }^{31}$ Ferroptosis is associated with pathogenic changes observed in PD, as well as the classical in vitro and in vivo pro-oxidant models. ${ }^{33}$ This includes nigral iron elevation, mitochondriopathy, glutathione depletion, lipid peroxidation, elevated ROS generation and oxidation of dopamine. ${ }^{33}$ Ferroptosis can be rescued by iron chelation (e.g. with DFP), ${ }^{31,33}$ supporting the requirement for iron in the initiation of this cell death pathway. Importantly, a range of inhibitors with greater specificity to ferroptosis (e.g. liproxstatin-1) have recently been designed with promising future implications in disease modification.

\section{A new therapeutic strategy of conservative chelation based on iron scavenging and redeployment}

The implication of siderosis and iron toxicity has largely been based on the protective effects of iron chelation in cell and animal models. ${ }^{1-3,7-11,34,35}$ However, for any chelator to be of clinical value in disorders of regional siderosis they ought to be endowed with a requisite accessibility to the relevant sites and differential specificity so as to spare unaffected areas of the organism from scavenging an essential element. ${ }^{36}$ Different agents with iron chelating features (e.g. deferoxamine, clioquinol, VK28, M30 and natural plant-derived polyphenol flavonoids) have been assessed but not progressed to clinical trial.

DFP is exceptional among iron chelators in its ability to cross membranes, including the blood brain barrier (BBB), and to chelate components of the cellular labile iron pool in brain tissue. $^{36}$ DFP has the remarkable ability of rescuing transfusional hemosiderosis in the heart 
of $\beta$-thalassemia patients without inducing anemia, largely attributable to the redeployment of captured iron to extracellular iron free Tf and subsequent distribution (Fig. 3). ${ }^{36}$

The conservative repositioning strategy has been applied to PD using DFP at the relatively low oral dose of $30 \mathrm{mg} / \mathrm{kg} / \mathrm{day} .{ }^{9}$ An early-stage PD patient pilot study using a delayed start paradigm (6 months DFP or placebo pretreatment followed by 12 months DFP for all) yielded a significant reduction in SNc siderosis, particularly in the group that started early with DFP. Compared to placebo this remained stable until completion (month 18). A concomitant clinical benefit was noted at 6 months with a 3-point improvement in the motor-unified Parkinson's disease rating scale (UPDRS) in the early start group (21.6 \pm 8$)$ versus the delayed start group (24 \pm 6$)$. Importantly, at 12 months these 'early start' patients retained a significantly lower motor handicap (1 point on the motor UPDRS: $21.3 \pm 8$ ) compared to the delayed start group $(22.8 \pm 6)$, signifying a disease modifying effect. ${ }^{9}$ The conservative mode of chelation was reflected by an absence of systemic iron loss with patients showing normal iron indices that were unaltered after 18 or 24 months DFP treatment (except a mild ferritin reduction in blood and cerebro-spinal fluid). Positive clinical outcomes were recently confirmed by another randomised double-blind, placebo controlled trial. In this smaller sized trial, DFP reduced dentate and caudate nucleus iron content and indicated a trend for improvement in motor-UPDRS scores and quality of life. ${ }^{37}$ In both trials DFP had a good safety profile; despite the requirement of weekly blood counts during the first 6 months to monitor reversible neutropenia that may occur in $1-3 \%$ of patients treated with DFP.

These promising results have now led to a large phase II, European multicentre, parallelgroup, placebo-controlled, randomized clinical trial, of which the aim is to evaluate whether DFP can slow progressive impairment in PD patients (www.fairpark2.eu). 338 patients with de novo PD are planned for randomization to either DFP (30 mg/kg/day in two doses a day) or placebo for 9 months. All will then participate in a 1-month post-treatment monitoring 
period. To assess the hypothesized disease-modifying effect of DFP the primary efficacy criterion will be the total score on the UPDRS, encompassing motor and non-motor symptoms as well as activities of daily living. Secondary criteria include cognition, quality of life, quantitative continuous motor activity in the home environment and a health economics questionnaire. Potential surrogate and theranostic biomarkers of efficacy and safety will also be analysed (i.e. wide range of iron, dopamine and $\alpha$-synuclein markers). These include the imaging measurement of iron content (MRI R2*/QSM and transcranial ultrasound) and dopamine content (dopamine transporter SPECT imaging). Since the initiation of the FAIRPARK-II trial a further phase II trial at sites in both Europe and Canada has begun to analyse different DFP doses ranging from 10 to $40 \mathrm{mg} / \mathrm{kg} /$ day to evaluate clinical outcome over the same treatment period.

\section{Conclusions and future directions}

Cell iron dyshomeostasis has been implicated in a wide range of neurodegenerative disorders other that PD, such as Alzheimer's disease (AD; cortical iron elevation), ${ }^{38}$ Amyotrophic lateral sclerosis (ALS; elevated iron in motor neuron pathways) ${ }^{39}$ and the less prevalent Brain Iron Accumulation (NBIA) neurodegenerative disorders. This maldistribution of iron might represent a pathological form of regional siderosis that could be treated by a conservative mode of chelation based on drug-mediated iron redistribution, as currently under clinical evaluation in PD, Pantothenate Kinase-Associated Neurodegeneration type 2, ALS and AD. The aim is to slowdown disease progression, but complementary strategies may also block iron-dependent death pathways such as ferroptosis or stimulate cell repair pathways that promote glutathione formation or inhibit iron dependent prolyl hydroxylases. ${ }^{9,33,40,}$ It is hoped that with new biomarker developments in iron sensitive MRI sequencing, clinical trials such as the one presented here for conservative iron chelation may change the future clinical practice of $\mathrm{PD}$. 


\section{ACKNOWLEDGMENTS}

The authors wish to thank the support of the Lille University Hospital and NS-Park/FCRIN clinical research network, the European commission for the grant $\mathrm{N}^{\circ} 633190$ of the $\mathrm{H} 2020$ program; NCT02655315. The authors also thank the Fédération de la Recherche Clinique du CHU de Lille, Pauline Guyon, Lucile Marguet, Stéphanie Le Naour, Florence Nosal, Amelie Michon, Aurélie Rabier for the support and ApoPharma for the drug provision in the clinical trials.

\section{FULL FINANCIAL DISCLOSURE FOR THE PREVIOUS 12 MONTHS}

Caroline Moreau has received grants from the France Parkinson charity. She has received various honoraria from pharmaceutical companies for consultancy and lectures on Parkinson's disease at symposia such as Aguettant, Abbvie, Medtronic, Novartis.

James Duce has received research funding from Alzheimer's Society, Alzheimer's Research UK, European Commission, Parkinson's UK and NHMRC. He serves as a scientific advisor on the FAIR-PARK II but has no financial disclosures.

Olivier Rascol has received research grants from Agence Nationale de la Recherche (ANR), CHU de Toulouse, France-Parkinson, INSERM-DHOS Recherche Clinique Translationnelle, MJFox Foundation, Programme Hospitalier de Recherche Clinique, European Commission (FP7, H2020). He has served on advisory boards, served as a consultant and given lectures for pharmaceutical companies such as AbbVie, Adamas, Acorda, Addex, AlzProtect, Apopharma, Astrazeneca, Bial, Biogen, Britannia, Clevexel, INC Reasearch, Lundbeck, Merck, MundiPharma, Neuroderm, Novartis, Oxford Biomedica, Parexel, Pfizer, Prexton Therapeutics, Quintiles, Sanofi, Servier, Sunovion, Teva, UCB, XenoPort, Zambon. Jean Christophe Devedjian has nothing to declare. 
Daniela Berg has received funds from the Michael J. Fox Foundation, Janssen Pharmaceutica N.V., German Parkinson's Disease Association (dPV), BMWi, BMBF, Parkinson Fonds Deutschland gGmbH, UCB Pharma GmbH, TEVA Pharma GmbH, EU, Novartis Pharma $\mathrm{GmbH}$, Lundbeck. She has served on advisory boards and received honoria for lectures of UCB Pharma GmbH, Lundbeck, Prexton Therapeutics, Novartis, BIAL and GE-Healthcare. David Dexter is receiving research funding from Imperial BRC, Parkinson's UK, Michael JFox Foundation. He serves as a scientific advisor on the FAIR-PARK II Horizon 2020 award but has no other financial disclosures.

Ioav Cabantchik consults for Aferrix Ltd (Israel) and Hinoman (Ltd) Israel and has been an invited speaker in meetings organized by Apopharma (Canada) for which he received lecturer honoraria.

Ashley I. Bush holds equity in: Prana Biotechnology Ltd, Cogstate Ltd, Mesoblast Ltd, Brighton Biotech LLC, Grunbiotics Pty Ltd, Eucalyptus Pty Ltd, Collaborative Medicinal Development LLC.

He is a payed consultant for Collaborative Medicinal Development Pty Ltd. David Devos has received PHRC grants from the French Ministry of Health and research funding from the ARSLA charity, France Parkinson charity, Credit Agricole Fundation. He has led two pilot investigator driven studies with DFP provided for free by ApoPharma (FAIRPARK-I and SAFE-FAIR ALS-I). He is leading two large investigator driven studies with DFP provided for free by ApoPharma (FAIRPARK-II and FAIR ALS-II). He served on advisory boards, served as a consultant and given lectures for pharmaceutical companies such as Orkyn, Aguettant, Abbvie, Medtronic, Novartis, Teva, UCB, Lundbeck. 


\section{AUTHORS CONTRIBUTION}

1) The research project: A: conception; B: organization; C: execution

2) The manuscript: A: writing of the first draft, B. review and critical comment

Caroline Moreau: A1, C1, A2, B2

James Duce: A1, C1, A2, B2

Olivier Rascol: A1, B1, C1, B2

JC Devedjian: B1, B2

David Dexter: B1, B2

Ioav Cabantchik: A2, B2

Ashley Bush: A2, B2

David Devos: A1, B1, C1, A2, B2

FAIRPARK II study group (with the support of the Lille University Hospital and NS-Park/FCRIN clinical research network, www.fairpark2.eu; funded by European commission grant $N^{\circ} 633190$ of the H2020 program; NCT02655315)

- Abbruzzese Giovanni University of Genove Italy

- Allain Marie-Anne ALLAIN CHU Lille France

- Anheim Mathieu, Department of Movement Disorders and Neurology, NS-Park/FCRIN Network, CHU Strasbourg, Strasbourg, France

- Bakker Martijn University Nijmegen Medical Center, Donders Institute Brain Cognition \& Behaviour Center for Neurosciences The Netherland

- Balzer-Geldsetzer Monika ipps University Hospital Essen, GermanyUniversitat Marburg

- Bargalló Núria Magnetic Resonance Unit, Neurorradiology Section, Centre de Diagnòstic per la Imatge (CDI), IDIBAPS, Hospital Clínic, Barcelona, Catalonia, Spain

- Barone Paolo University of Salerno Italy

- Basenau Sandra, Philipps Universitat Marburg, Germany

- Benchetrit Eve ICM, Hôpital Pitié-Salpêtrière, Paris, France

- Berg Daniela, Department of Neurology, Christian-Albrechts-University of Kiel, Kiel, Germany

- Bloem Bas University Nijmegen Medical Center, Donders Institute Brain Cognition \& Behaviour Center for Neurosciences The Netherland

- Boraud Thomas Université de Bordeaux, Institut des Maladies Neurodégénératives, UMR CNRS 5293 and Department of Neurology, NS-Park/FCRIN Network, CHU de Bordeaux, Bordeaux, France

- Bordet Regis, University de Lille, CHU de Lille, INSERM UMRS_1171, Service de Pharmacologie Clinique LICEND COEN Center Lille, France

- Bouca Raquel Instituto de Medicina Molecular Lisboa Portugal

- Bourdain Frédéric, Hôpital Foch, Suresnes, France

- Bouzas Jimena European Clinical Research Infrastructure Network-ERIC, France

- Brefel-Courbon Christine, CHU de Toulouse, INSERM; Centre d'Investigation Clinique CIC1436, Services de Neurologie et de Pharmacologie Clinique, NS-Park/FCRIN Network, Toulouse, France

- Bubenheim Michael CHU-Hôpitaux de Rouen France

- Burn David, Faculty of Medical Sciences Newcastle University United Kingdom

- Bush Ashley I., Oxidation Biology Unit, The Florey Institute of Neuroscience and Mental Health, The University of Melbourne, Parkville, Victoria, Australia

- Cabantchik Ioav, Della Pergola Chair, Alexander Silberman Institute of Life Sciences, Hebrew University, Jerusalem, 91904, Israel 
- Calvas Fabienne, CHU de Toulouse, INSERM; Centre d'Investigation Clinique CIC1436, Services de Neurologie et de Pharmacologie Clinique, NS-Park/FCRIN Network, Toulouse, France

- Cámara Ana Parkinson's disease \& Movement Disorders Unit, Neurology Service, Hospital Clínic de Barcelona, IDIBAPS, University of Barcelona, CIBERNED, Barcelona, Catalonia, Spain

- Carrière Nicolas, University de Lille, CHU de Lille, INSERM UMRS_1171, Service de Neurologie NSPark/FCRIN Network LICEND COEN Center Lille, France

- Chaigneau Véronique, NS-Park/FCRIN Network, Toulouse, France

- Compta Yaroslau, Parkinson's disease \& Movement Disorders Unit, Neurology Service, Hospital Clínic de Barcelona, IDIBAPS Barcelona, Catalonia, Spain

- Connelly John, ApoPharma Inc., Toronto, Canada

- Cormier-Dequaire Florence Hôpital Pitié-Salpêtrière, Paris, France

- Corvol Jean-Christophe, Sorbonne Universités, UPMC Univ Paris 06, and INSERM UMRS_1127 and CIC_1422, and CNRS UMR_7225, and AP-HP, and ICM, Hôpital Pitié-Salpêtrière, NS-Park/FCRIN Network, Département des maladies du système nerveux, Paris, France

- Cranston Amy University of Newcastle upon Tyne UK

- De Bie Rob, Academisch Medisch Centrum Universiteit van Amsterdam.Amsterdam, Netherlands

- De Marzi Roberto, Department of Neurology, Medical University Innsbruck, Innsbruck, Austria

- Defebvre Luc, University de Lille, CHU de Lille, INSERM UMRS_1171, Service de Neurologie NSPark/FCRIN Network LICEND COEN Center Lille, France

- Degos Bertrand Hôpital Pitié-Salpêtrière, Paris, France

- Demotes Jacques, European Clinical Research Infrastructure Network-ERIC, France

- Dellapina Estelle, NS-Park/FCRIN Network, Toulouse, France

- Deplanque Dominique, University de Lille, CHU de Lille, INSERM UMRS_1171, Service de Pharmacologie Clinique et CIC-CHU Lille, LICEND COEN Center Lille, France

- Devedjian Jean-Christophe, University de Lille, CHU de Lille, INSERM UMRS_1171, NS-Park/FCRIN Network LICEND COEN Center Lille, France

- Devos David, University de Lille, CHU de Lille, INSERM UMRS_1171, Service de Pharmacologie Clinique et service de Neurologie NS-Park/FCRIN Network LICEND COEN̄ Center Lille, France

- Dexter David, Imperial College London London United Kingdom

- Dodel Richard, University Hospital Essen, GermanyPhilipps Universitat Marburg Germany

- Dongmo Carole Hôpital Pitié-Salpêtrière, Paris, France

- Duce James, School of Biomedical Sciences, Faculty of Biological Sciences, University of Leeds, Leeds, West Yorkshire, UK \& Oxidation Biology Unit, The Florey Institute of Neuroscience and Mental Health, The University of Melbourne, Parkville, Victoria, Australia

- Duhamel Alain, CHU Lille France

- Dupouy Julia, CHU de Toulouse, INSERM; Centre d'Investigation Clinique CIC1436, Services de Neurologie et de Pharmacologie Clinique, NS-Park/FCRIN Network, Toulouse, France

- Durif Franck, Department of Movement Disorders and Neurology, NS-Park/FCRIN Network, CHU ClermontFerrand, Clermont-Ferrand, France

- Dusek Petr, Dept. of Neurology, Charles University, Prague, Czech Republic

- Eusebio Alexandre, Department of Neurology and Movement Disorders - APHM Timone University Hospital and Institut de Neurosciences de la Timone, NS-Park/FCRIN Network, AMU-CNRS UMR 7289, Marseille, France

- Eyvrard Frédéric, Pharmacy, CHU de Toulouse, Toulouse, France

- Fernández Manel Parkinson's disease \& Movement Disorders Unit, Neurology Service, Hospital Clínic de Barcelona, IDIBAPS, University of Barcelona, CIBERNED, Barcelona, Catalonia, Spain

- Ferreira Joaquim, Instituto de Medicina Molecular Lisboa Portugal

- Forni Gian Luca, Ospedia Galliera Italy

- Foubert-Samier Alexandra Université de Bordeaux, Institut des Maladies Neurodégénératives, UMR CNRS 5293 and Department of Neurology, NS-Park/FCRIN Network, CHU de Bordeaux, Bordeaux, France

- Fradette Caroline, ApoPharma Inc., Toronto, Canada

- Fréville Laëtitia, Centre pour l'Acquisition et le Traitement des Images (www.cati-neuroimaging.com); Sorbonne Universités, UPMC Univ Paris 06, CNRS, INSERM, Laboratoire d'Imagerie Biomédicale, F-75013, Paris, France

- Galitzky Monique, CHU de Toulouse, INSERM; Centre d'Investigation Clinique CIC1436, Services de Neurologie et de Pharmacologie Clinique, NS-Park/FCRIN Network, Toulouse, France

- Gaudebout Cecile Hôpital Pitié-Salpêtrière, Paris, France

- Gelé Patrick CHU de Lille CHU Lille France

- Giladi Nir Tel Aviv Sourasky Medical Center Israel

- Grabli David Hôpital Pitié-Salpêtrière, Paris, France 
- Grolez Guillaume University de Lille, CHU de Lille, INSERM UMRS_1171, Service de Neurologie NSPark/FCRIN Network LICEND COEN Center Lille, France

- Guyon Pauline CHU Lille France

- Habert Marie-Odile, Sorbonne Universités, UPMC Univ Paris 06, CNRS, INSERM, Laboratoire d'Imagerie Biomédicale, AP-HP, Hôpital Pitié-Salpêtrière, Département de Médecine Nucléaire, F-75013, Paris, France

- Harroch Estelle, CHU de Toulouse, INSERM; Centre d'Investigation Clinique CIC1436, Services de Neurologie et de Pharmacologie Clinique, Toulouse, France

- Hartmann Andreas Hôpital Pitié-Salpêtrière, Paris, France

- Hirsch Denise, INSERM - Transfert SA Paris

- Hopfner Franziska Department of Neurology, Christian-Albrechts-University of Kiel, Kiel, Germany

- Jurado Camille, Pharmacy, CHU de Toulouse, Toulouse, France

- Kaiser Andreas Medizinische Universitat Innsbruck Austria

- Klaus Seppi Medizinische Universitat Innsbruck

- Kouassi Nadège, CHU de Toulouse, INSERM; Centre d'Investigation Clinique CIC1436, Services de Neurologie et de Pharmacologie Clinique, Toulouse, France

- Labreuch Julien CHU de Lille CHU Lille France

- Lacomblez Lucette Hôpital Pitié-Salpêtrière, Paris, France

- Lanthaler Barbara Medizinische Universitat Innsbruck Austria

- Le Forestier Nadine Assistance Publique - Hôpitaux de Paris France

- Le Naour Stéphanie INSERM - Transfert SA Paris France

- Le Toullec Benjamin Hôpital Pitié-Salpêtrière, Paris, France

- Locatelli Maxime, Centre pour l'Acquisition et le Traitement des Images (www.cati-neuroimaging.com); ICM Institut du Cerveau et de la Moelle épinière, CNRS UMR7225, INSERM U1127, UPMC, F-75013, Paris, France

- Lomeña Francisco Nuclear Medicine Department, Hospital Clínnic, IDIBAPS, University of Barcelona, CIBERSAM, Barcelona, Catalonia, Spain

- Longato Nadine Department of Movement Disorders and Neurology, NS-Park/FCRIN Network, CHU Strasbourg, Strasbourg, France

- Lützen Ulf Department of Nuclear Medicine, Molecular Diagnostic Imaging and Therapy, University Hospital of Schleswig-Holstein (UKSH), Campus Kiel, Germany

- Maetzler Corina Department of Neurology, Christian-Albrechts-University of Kiel, Kiel, Germany

- Maetzler Walter, Department of Neurology, Christian-Albrechts-University of Kiel, Kiel, Germany

- Mahlknecht Philipp Medizinische Universitat Innsbruck Austria

- Mangone Graziella Hôpital Pitié-Salpêtrière, Paris, France

- Mariani Louise-Laure Hôpital Pitié-Salpêtrière, Paris, France

- Marques Ana, Department of Movement Disorders and Neurology, NS-Park/FCRIN Network, CHU ClermontFerrand, Clermont-Ferrand, France

- Matthias Löhle, MD, Department of Neurology, University of Rostock, Rostock, Germany

- Meissner Wassilios G., Université de Bordeaux, Institut des Maladies Neurodégénératives, UMR CNRS 5293 and Department of Neurology, NS-Park/FCRIN Network, CHU de Bordeaux, Bordeaux, France

- Michon Amelie, European Clinical Research Infrastructure Network-ERIC, France

- Moreau Caroline, University de Lille, CHU de Lille, INSERM UMRS_1171, Service de Neurologie NSPark/FCRIN Network LICEND COEN Center Lille, France

- Nardocci Nardo Nardocci Istitu Besta Italy

- Nosal Florence CHU de Lille France

- Nyholm Dag Uppsala University Sweden

- Oeckl Patrick Universitaet Ulm Germany

- Ory Fabienne, CHU de Toulouse, INSERM; Centre d'Investigation Clinique CIC1436, Services de Neurologie et de Pharmacologie Clinique, Toulouse, France

- Otto Markus, Universitaet Ulm Germany

- Ouk Thavarak University de Lille, CHU de Lille, INSERM UMRS_1171, Service de Neurologie NSPark/FCRIN Network LICEND COEN Center Lille, France

- Pavese Nicola University of Newcastle upon Tyne UK

- Peball Marina Medizinische Universitat Innsbruck Austria

- Phillips Clélie Department of Movement Disorders and Neurology, NS-Park/FCRIN Network, CHU Strasbourg, Strasbourg, France

- Pineau Fanny Hôpital Pitié-Salpêtrière, Paris, France

- Planellas Lluís Parkinson's disease \& Movement Disorders Unit, Neurology Service, Hospital Clínic de Barcelona, IDIBAPS, University of Barcelona, CIBERNED, Barcelona, Catalonia, Spain

- Poewe Werner, Department of Neurology, Medical University Innsbruck, Innsbruck, Austria 
- Pop-Ilieva Lydia, ApoPharma Inc., Toronto, Canada

- Post Bart, Radboud University Nijmegen Medical Center, Donders Institute Brain Cognition \& Behaviour Center for Neurosciences The Netherland

- Rabier Aurélie Inserm NS-Park/FCRIN Network, Toulouse, France

- Rascol Olivier, Université de Toulouse, UPS, CHU de Toulouse, INSERM; Centre d'Investigation Clinique CIC1436, Services de Neurologie et de Pharmacologie Clinique, UMR TONIC, NS-Park/FCRIN Network, NeuroToul COEN Center, Toulouse, France

- Riedel Christian Department of Neuroradiology, Christian Albrechts University, Kiel, Germany

- Rodrigues Maura Hôpital Pitié-Salpêtrière, Paris, France

- Rose Christian Hopital Saint-Vincent-de-Paul Lille France

- Roullet-Solignac Isabelle Movement Disorders Unit, Hopital Neurologique, Hospices Civils de Lyon, Université de Lyon, Université Claude Bernard Lyon 1, CNRS Institut des Sciences Cognitives, Centre de Neurosciences, Cognitives, UMR 5229, NS-Park/FCRIN Network, Bron Lyon France

- Rozova Anna, ApoPharma Inc., Toronto, Canada

- Růžička Evžen, Dept. of Neurology, Charles University, Prague, Czech Republic

- Salis Alexandra, Inserm NS-Park/FCRIN Network, Toulouse, France

- Schäffer Eva Department of Neurology, University Hospital Schleswig-Holstein, Christian-Albrechts University Kiel, Germany

- Scherfler Christoph Department of Neurology, Medical University Innsbruck, Innsbruck, Austria

- Schiefermeier Natalia, Department of Neurology, Medical University Innsbruck, Innsbruck, AustriaSeppi Klaus Department of Neurology, Medical University Innsbruck, Innsbruck, AustriaSmagghe Delphine, INSERM - Transfert SA Paris France

- Silva Tânia, Instituto de Medicina Molecular Lisboa Portugal

- Socha Julie Hôpital Pitié-Salpêtrière, Paris, France

- Souyris Corinne, CHU de Toulouse, INSERM; Centre d'Investigation Clinique CIC1436, Services de Neurologie et de Pharmacologie Clinique, Toulouse, France

- Spampinato Umberto Université de Bordeaux, Institut des Maladies Neurodégénératives, UMR CNRS 5293 and Department of Neurology, NS-Park/FCRIN Network, CHU de Bordeaux, Bordeaux, France

- Spino Michael, ApoPharma Inc., Toronto, Canada

- Steel Alison University of Newcastle upon Tyne UK

- Sweta Bajaj Medizinische Universitat Innsbruck Austria

- Thalamas Claire, CHU de Toulouse, INSERM; Centre d'Investigation Clinique CIC1436, Services de Neurologie et de Pharmacologie Clinique, Toulouse, France

- Teodor Danaila Movement Disorders Unit, Hopital Neurologique, Hospices Civils de Lyon, Université de Lyon, Université Claude Bernard Lyon 1, CNRS Institut des Sciences Cognitives, Centre de Neurosciences, Cognitives, UMR 5229, NS-Park/FCRIN Network, Bron Lyon France

- Teresa Anna Instituto de Medicina Molecular Lisboa Portugal

- Thibault Laetitia, CHU Lille France

- Thobois Stéphane, Movement Disorders Unit, Hopital Neurologique, Hospices Civils de Lyon, Université de Lyon, Université Claude Bernard Lyon 1, CNRS Institut des Sciences Cognitives, Centre de Neurosciences, Cognitives, UMR 5229, NS-Park/FCRIN Network, Bron Lyon FranceFrance

- Tison François Université de Bordeaux, Institut des Maladies Neurodégénératives, UMR CNRS 5293 and Department of Neurology, NS-Park/FCRIN Network, CHU de Bordeaux, Bordeaux, France

- Tolosa Eduardo, Parkinson's disease \& Movement Disorders Unit, Neurology Service, Hospital Clínic de Barcelona, IDIBAPS, University of Barcelona, CIBERNED, Barcelona, Catalonia, Spain

- Tranchant Christine, Department of Movement Disorders and Neurology, NS-Park/FCRIN Network, CHU Strasbourg, Strasbourg, France

- Tricta Fernando, ApoPharma Inc., Toronto, Canada

- Trifirò Gianluca Trifirò University of Messina \& Erasmus Medical Center, Rotterdam The Netherlands

- Uwe Walter, MD, Department of Neurology, University of Rostock, Rostock, Germany

- Vidailhet Marie Hôpital Pitié-Salpêtrière, Paris, France

- Wang Yi, PhD, Departments of Radiology and Biomedical Engineering, Cornell University, New York, USA

- Werkmann Mario Medizinische Universitat Innsbruck Austria

- Yilmas Rezzak Department of Neurology, University Hospital Schleswig-Holstein, Christian-Albrechts University Kiel, Germany

- You Hana Hôpital Pitié-Salpêtrière, Paris, France

- Zeuner Kirsten Department of Neurology, University Hospital Schleswig-Holstein, Christian-Albrechts University Kiel, Germany

- The investigators of the 24 centres 


\section{REFERENCES}

1. Ward RJ, Zucca FA, Duyn JH, Crichton RR, Zecca L. The role of iron in brain ageing and neurodegenerative disorders. Lancet Neurol. 2014; 13:1045-60.

2. Belaidi, A. A. \& Bush, A. I. Iron neurochemistry in Alzheimer's disease and Parkinson’s disease: targets for therapeutics. J Neurochem 2016; 139 Suppl 1:179-197.

3. Matak P, Matak A, Moustafa S et al. Disrupted iron homeostasis causes dopaminergic neurodegeneration in mice. Proc Natl Acad Sci U S A 2016; 113, 3428-3435, in which low dopaminergic iron status was associated with development of Parkinsons in a mouse model.

4. Hare DJ, Double KL. Iron and dopamine: a toxic couple. Brain. 2016; 139:1026-35.

5. Holmes-Hampton GP1, Chakrabarti M, Cockrell AL, McCormick SP, Abbott LC, Lindahl LS, Lindahl PA. Changing iron content of the mouse brain during development. Metallomics. 2012;4:761-70.

6. Guzman JN, Sanchez-Padilla J, Wokosin D, Kondapalli J, Ilijic E, Schumacker PT, Surmeier DJ. Oxidant stress evoked by pacemaking in dopaminergic neurons is attenuated by DJ-1. Nature. 2010; 468:696-700.

7. Ayton S, Lei P, Duce JA, Wong BX, Sedjahtera A, Adlard PA, Bush AI, Finkelstein DI. Ceruloplasmin dysfunction and therapeutic potential for Parkinson disease. Ann Neurol 2013; 73:554-559.

8. Ayton S, Lei P, Hare DJ, Duce JA, George JL, Adlard PA, McLean C, Rogers JT, Cherny RA, Finkelstein DI, Bush AI. Parkinson's disease iron deposition caused by nitric oxideinduced loss of $\beta$-amyloid precursor protein. J Neurosci. 2015; 35:3591-7.

9. Devos D, Moreau C, Devedjian JC, Kluza J, Petrault M, Laloux C, et al. Targeting chelatable iron as a therapeutic modality in Parkinson's disease. Antioxid Redox Signal 2014; 21:195-210. 
10. Kaur D, Yantiri F, Rajagopalan S, Kumar J, Mo JQ, Boonplueang R, et al. Genetic or pharmacological iron chelation prevents MPTP-induced neurotoxicity in vivo: a novel therapy for Parkinson's disease. Neuron 2003; 37:899-909.

11. Lei P, Ayton S, Appukuttan AT, Volitakis I, Adlard PA, Finkelstein DI, Bush AI. Clioquinol rescues Parkinsonism and dementia phenotypes of the tau knockout mouse. Neurobiol Dis. 2015; 81:168-75.

12. Ulla M, Bonny JM, Ouchchane L, Rieu I, Claise B, Durif F. Is R2* a new MRI biomarker for the progression of Parkinson's disease? A longitudinal follow-up. PLoS One. 2013; 8:e57904.

13. Hopes L, Grolez G, Moreau C, Lopes R, Ryckewaert G, Carrière N, Auger F, Laloux C, Petrault M, Devedjian JC, Bordet R, Defebvre L, Jissendi P, Delmaire C, Devos D. Magnetic Resonance Imaging Features of the Nigrostriatal System: Biomarkers of Parkinson's Disease Stages? PLoS One. 2016; 11:e0147947

14. Wang JY, Zhuang QQ, Zhu LB, Zhu H, Li T, Li R, Chen SF, Huang CP, Zhang X, Zhu JH. Meta-analysis of brain iron levels of Parkinson's disease patients determined by postmortem and MRI measurements. Sci Rep. 2016; 6:36669.

15. Mahlknecht P, Krismer F, Poewe W, Seppi K. Meta-analysis of dorsolateral nigral hyperintensity on magnetic resonance imaging as a marker for Parkinson's disease. Mov Disord. 2017 [Epub ahead of print]

16. Bunzeck N, Singh-Curry V, Eckart C, Weiskopf N, Perry RJ, Bain PG, et al. Motor phenotype and magnetic resonance measures of basal ganglia iron levels in Parkinson's disease. Parkinsonism Relat Disord 2013; 19:1136-1142.

17. Acosta-Cabronero J, Cardenas-Blanco A, Betts MJ, Butryn M, Valdes-Herrera JP, Galazky I, Nestor PJ. The whole-brain pattern of magnetic susceptibility perturbations in Parkinson's disease. Brain. 2017; 140:118-131. 
18. Chen W, Zhu W, Chang S, Lou M, Kopell BH, Kaplitt MG, Devos D, Hirai T, Huang X, Korogi Y, Shtilbans A, Jahng GH, Pelletier D, Gauthier SA, Pitt D, Bush AI, Brittenham GM, Prince MR. Clinical quantitative susceptibility mapping (QSM): Biometal imaging and its emerging roles in patient care. J Magn Reson Imaging. 2017 [Epub ahead of print]

19. Huddleston DE, Langley J, Sedlacik J, Boelmans K, Factor SA, Hu XP. In vivo detection of lateral-ventral tier nigral degeneration in Parkinson's disease. Hum Brain Mapp. 2017 [Epub ahead of print]

20. Berg D, Roggendorf W, Schröder U, Klein R, Tatschner T, Benz P, Tucha O, Preier M, Lange KW, Reiners K, Gerlach M, Becker G. Echogenicity of the substantia nigra: association with increased iron content and marker for susceptibility to nigrostriatal injury. Arch Neurol. 2002; 59:999-1005.

21. Zecca L, Berg D, Arzberger T, Ruprecht P, Rausch WD, Musicco M, Tampellini D, Riederer P, Gerlach M, Becker G. In vivo detection of iron and neuromelanin by transcranial sonography: a new approach for early detection of substantia nigra damage. Mov Disord. $2005 ; 20: 1278-85$.

22. Lei P, Ayton S, Finkelstein DI, Spoerri L, Ciccotosto GD, Wright DK, Wong BX, Adlard PA, Cherny RA, Lam LQ, Roberts BR, Volitakis I, Egan GF, McLean CA, Cappai R, Duce JA, Bush AI. Tau deficiency induces parkinsonism with dementia by impairing APPmediated iron export. Nat Med 2012; 18:291-295.

23. Hochstrasser H, Tomiuk J, Walter U, Behnke S, Spiegel J, Krüger R, et al. Functional relevance of ceruloplasmin mutations in Parkinson's disease. FASEB J. 2005; 19:1851-3.

24. Wu KC, Liou HH, Kao YH, Lee CY, Lin CJ. The critical role of Nramp1 in degrading $\alpha$ synuclein oligomers in microglia under iron overload condition. Neurobiol Dis. 2017; 104:6172. 
25. Rhodes SL, Buchanan DD, Ahmed I, Taylor KD, Loriot MA, Sinsheimer JS, Bronstein JM, Elbaz A, Mellick GD, Rotter JI, Ritz B. Pooled analysis of iron-related genes in Parkinson's disease: association with transferrin. Neurobiol Dis. 2014; 62:172-8.

26. Faucheux BA, Nillesse N, Damier P, Spik G, Mouatt-Prigent A, Pierce A, Leveugle B, Kubis N, Hauw JJ, Agid Y, et al. Expression of lactoferrin receptors is increased in the mesencephalon of patients with Parkinson disease. Proc Natl Acad Sci U S A. 1995; 92:96037.

27. Salazar J, Mena N, Hunot S, Prigent A, Alvarez-Fischer D, Arredondo M, Duyckaerts C, Sazdovitch V, Zhao L, Garrick LM, Nuñez MT, Garrick MD, Raisman-Vozari R, Hirsch EC. Divalent metal transporter 1 (DMT1) contributes to neurodegeneration in animal models of Parkinson's disease. Proc Natl Acad Sci U S A. 2008;105:18578-83.

28. Duce J, Wong B, Durham H, Devedjian JC, Smith D, Devos D. Post translational changes to $\alpha$-synuclein control iron and dopamine trafficking; a concept for neuron vulnerability in Parkinson's disease. Mol Neurodegener. 2017;12:45.

29. Finkelstein DI, Hare DJ, Billings JL, Sedjahtera A, Nurjono M, Arthofer E, George S, Culvenor JG, Bush AI, Adlard PA. Clioquinol Improves Cognitive, Motor Function, and Microanatomy of the Alpha-Synuclein hA53T Transgenic Mice. ACS Chem Neurosci. 2016; 7:119-29.

30. Carboni E, Tatenhorst L, Tönges L, Barski E, Dambeck V, Bähr M, Lingor P. Deferiprone Rescues Behavioral Deficits Induced by Mild Iron Exposure in a Mouse Model of AlphaSynuclein Aggregation. Neuromolecular Med. 2017 Jun 16. [Epub ahead of print]

31. Dixon SJ, Lemberg KM, Lamprecht MR, Skouta R, Zaitsev EM, Gleason CE, Patel DN, Bauer AJ, Cantley AM, Yang WS, Morrison B 3rd, Stockwell BR. Ferroptosis: an irondependent form of nonapoptotic cell death. Cell. 2012; 149:1060-72. 
32. Friedmann Angeli JP, Schneider M, Proneth B, Tyurina YY, Tyurin VA, Hammond VJ, Herbach N, Aichler M, Walch A, Eggenhofer E, Basavarajappa D, Rådmark O, Kobayashi S, Seibt T, Beck H, Neff F, Esposito I, Wanke R, Förster H, Yefremova O, Heinrichmeyer M, Bornkamm GW, Geissler EK, Thomas SB, Stockwell BR, O'Donnell VB, Kagan VE, Schick JA, Conrad M. Inactivation of the ferroptosis regulator Gpx4 triggers acute renal failure in mice. Nat Cell Biol. 2014; 16:1180-91.

33. Do Van B, Gouel F, Jonneaux A, Timmerman K, Gele P, Petrault M, Bastide M, Laloux C, Moreau C, Bordet R, Devos D, Devedjian JC. Ferroptosis, a newly characterized form of cell death in Parkinson's disease that is regulated by PKC. Neurobiol Dis 2016; 94:169-178.

34. Weinreb O, Mandel S, Youdim MB, Amit T. Targeting dysregulation of brain iron homeostasis in Parkinson's disease by iron chelators. Free Radic Biol Med. 2013; 62:52-64.

35. Workman DG, Tsatsanis A, Lewis FW, Boyle JP, Mousadoust M, Hettiarachchi NT, Hunter M, Peers CS, Tétard D, Duce JA. Protection from neurodegeneration in the 6hydroxydopamine (6-OHDA) model of Parkinson's with novel 1-hydroxypyridin-2-one metal chelators. Metallomics. 2015; 7:867-76.

36. Cabantchik ZI, Munnich A, Youdim MB, Devos D. Regional siderosis: a new challenge for iron chelation therapy. Front Pharmacol. 2013; 4:167

37. Martin-Bastida A, Ward R, Newbould R, Piccini P, Sharp D, Kabba C, Patel M, Spino M, Connelly J, Tricta F, Crichton R, Dexter D. Brain iron chelation by deferiprone in a phase 2 randomised double-blinded placebo controlled clinical trial in Parkinson's disease. Sci Rep. $2017 ; 7: 1398$.

38. Ayton S, Fazlollahi A, Bourgeat P, Raniga P, Ng A, Lim YY, Diouf I, Farquharson S, Fripp J, Ames D, Doecke J, Desmond P, Ordidge R, Masters CL, Rowe CC, Maruff P, Villemagne VL; Australian Imaging Biomarkers and Lifestyle (AIBL) Research Group, 
Salvado O, Bush AI. Cerebral quantitative susceptibility mapping predicts amyloid- $\beta$-related cognitive decline. Brain. 2017;140:2112-2119.

39. Adachi Y, Sato N, Saito Y, Kimura Y, Nakata Y, Ito K, Kamiya K, Matsuda H, Tsukamoto T, Ogawa M. Usefulness of SWI for the Detection of Iron in the Motor Cortex in Amyotrophic Lateral Sclerosis. J Neuroimaging. 2015; 25:443-51.

40. Rajagopalan S, Rane A, Chinta SJ, Andersen JK. Regulation of ATP13A2 via PHD2HIF1 $\alpha$ Signaling Is Critical for Cellular Iron Homeostasis: Implications for Parkinson's Disease. J Neurosci. 2016; 36:1086-95.

\section{LEGENDS}

Figure 1: Iron overload in the Substantia Nigra

Post mortem mesencephalon analysis reveals that the dopaminergic neurons, naturally stained in black by auto-oxidation of dopamine in control (upper left), have disappeared in PD (upper right). Perls staining with a pink colour enhancement shows that SN is normally rich in iron $\left(2^{\text {nd }}\right.$ line left) but is iron overloaded in $\mathrm{PD}\left(2^{\text {nd }}\right.$ line right). Brain magnetic resonance imaging of the mesencephalon The quantitative weighted $\mathrm{T} 2 *$ sequence shows a higher intensity $(\mathrm{R} 2 *=1 / \mathrm{T} 2 *)$ in $\mathrm{PD}$ (bottom right) than in control (bottom left). The quantitative susceptibility mapping ( 3 Tesla) distinguishes the iron in the normal SN ( $3^{\text {rd }}$ line left) but the same nuclei in the iron overloaded PD case exhibits hyperintensity ( $3^{\text {rd }}$ line right). Above the $\mathrm{SN}$, the red nucleus can be identified.

Figure 2. Ferroptosis as a therapeutic target in Parkinson's disease. Alterations in the iron regulatory pathway and phospholipid oxidation are implicated in Parkinson's disease pathology. Increased intracellular iron occurs by enhanced import of iron within transferrin (Tf) through Transferrin receptor (TfR) endocytosis that is promoted by $\alpha$-synuclein ( $\alpha$-syn), and increased import of $\mathrm{Fe}^{2+}$ through the divalent metal transporter 1 (DMT1). In addition, 
iron export is impaired through the destabilization of ferroportin (Fpn) on the cell surface by $\beta$-amyloid precursor protein (APP) or ceruloplasmin (CP). When the storage protein neuromelanin $(\mathrm{Nm})$ and ferritin $(\mathrm{Ft})$ are no longer able to safely store intracellular iron, the labile pool of iron is elevated and catalyzes the formation of phospholipid hydroperoxides.

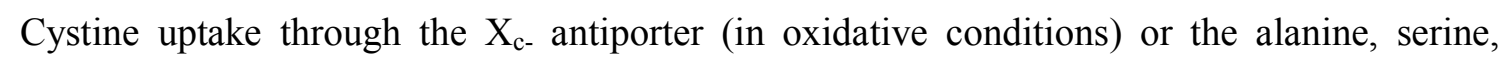
cysteine - preferring (ASC) system (in reducing conditions) is required for biosynthesis of glutathione (GSH). Glutathione peroxidase 4 (Gpx4) uses 2 GSH molecules to safely reduce phospholipid hydroperoxides to their corresponding lipid-alcohols, producing $\mathrm{H}_{2} \mathrm{O}$ and glutathione disulphide (GSSG) as byproducts. Elevated levels of intracellular iron with depletion of Gpx4, as evidenced in models of PD, promotes the accumulation of phospholipid hydroperoxides leading to a disruption in membrane integrity through a ferroptotic pathway. Reducing the labile iron pool (i.e deferiprone) or depleting the phospholipid hydroperoxides (i.e. liproxstatin-1 or ferrostatin-1) are thus promising targets for inhibiting ferroptosis in PD pathology.

Figure 3: A conservative mode of chelation based on: a. the scavenging of iron that accumulated intracellularly (organelle, cell, or tissue), and b. its redeployment to another cell or tissue compartment, either by the chelator or via iron transferred to circulating transferrin. The presence of apo-transferrin in circulating fluids ensures that iron scavenged from cells is conserved and redeployed primarily to areas of iron deficiency.

\section{Table summarizing main points of interest to a broad readership of general neurologists}

PD: Parkinson's disease; SNc: Substantia nigra pars compacta; SNr: Substantia nigra pars reticulate; VTA: Ventral Tegmental Area MRI: Magnetic resonance Imaging; SWI: susceptibility weighted imaging; ROS: reactive oxygen species; 6-OHDA: 6hydroxydopamine; ALS: amyotrophic lateral sclerosis; PKAN-2: Pantothenate Kinase- 
Associated Neurodegeneration type 2; AD: Alzheimer's disease. The table does not contain the exhaustive list of references on each topic. Reviews are frequently quoted due to space and references limitation. 


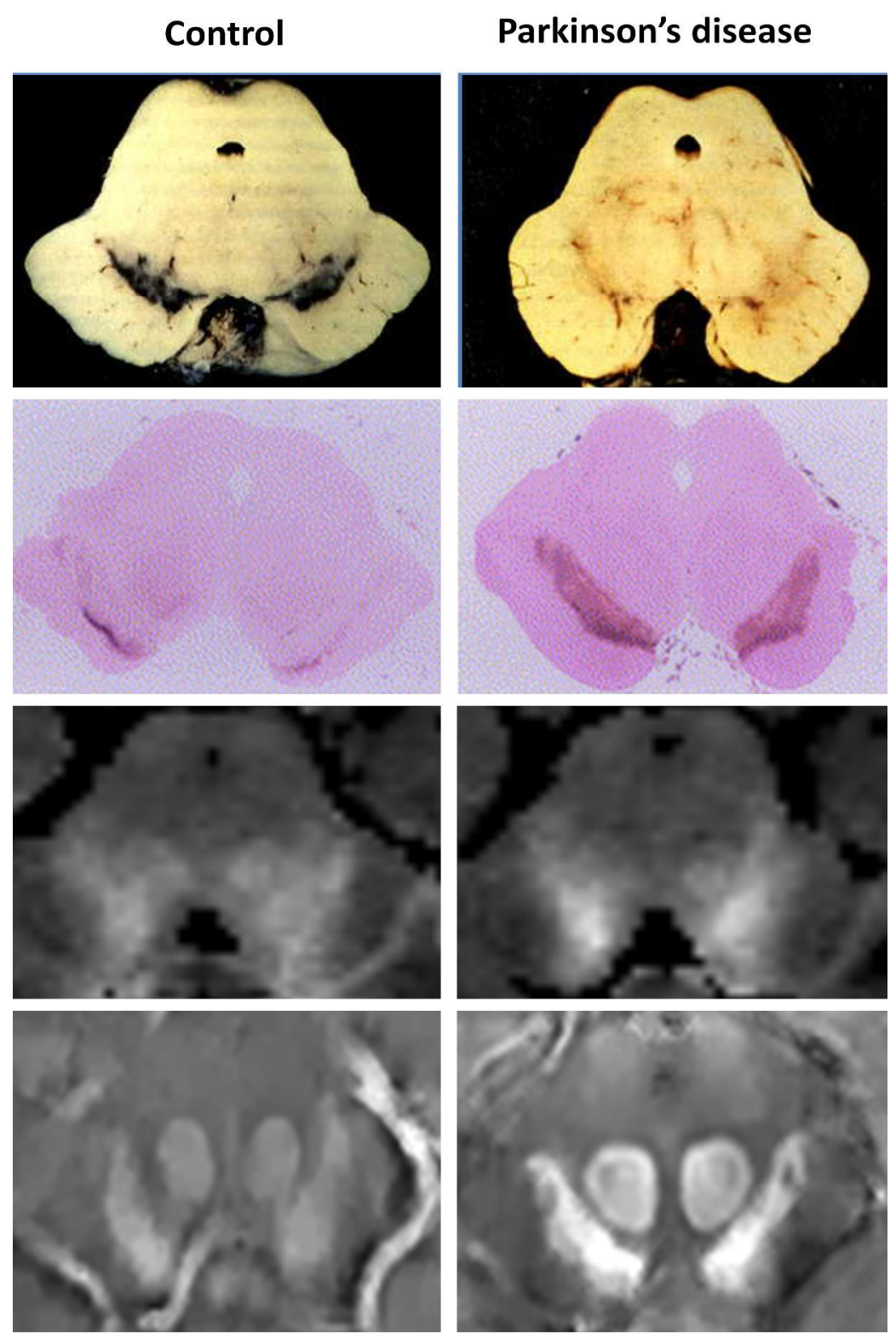

Figure 1 high resolution

$287 \times 437 \mathrm{~mm}(300 \times 300$ DPI $)$ 


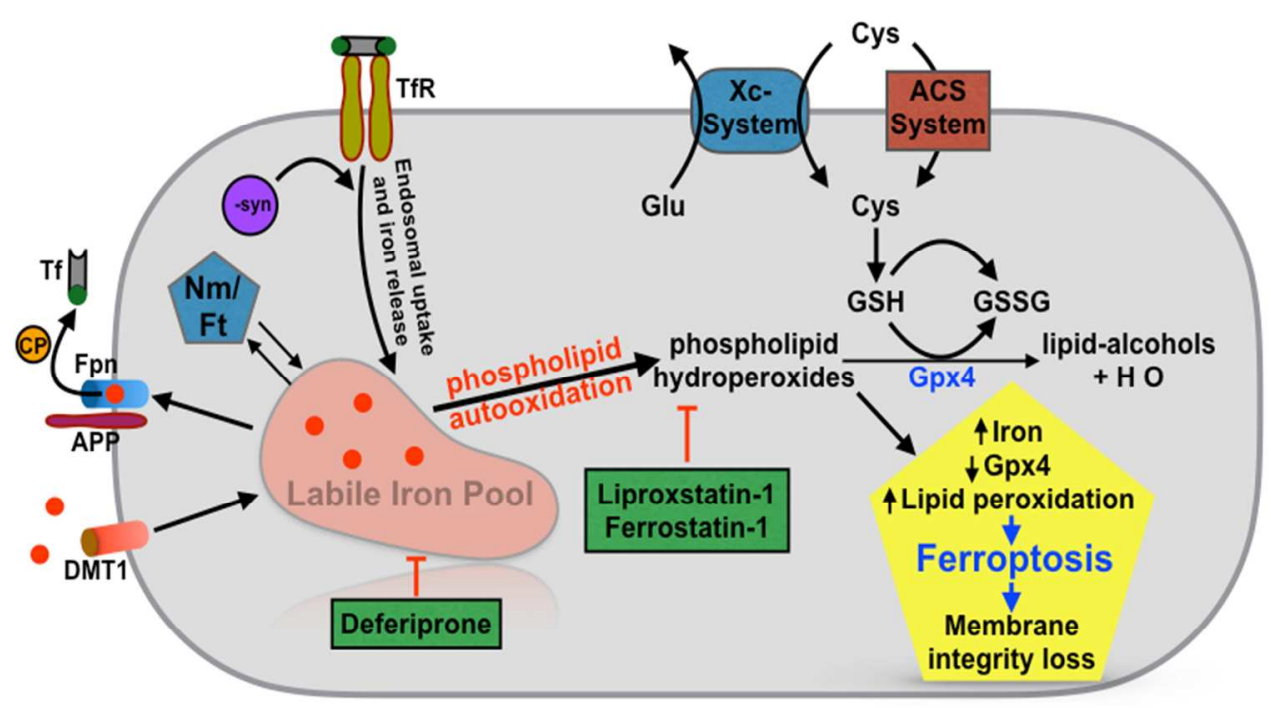

Figure 2

$323 \times 187 \mathrm{~mm}(300 \times 300$ DPI) 


\section{CELL OR TISSUE IRON REDISTRIBUTION}

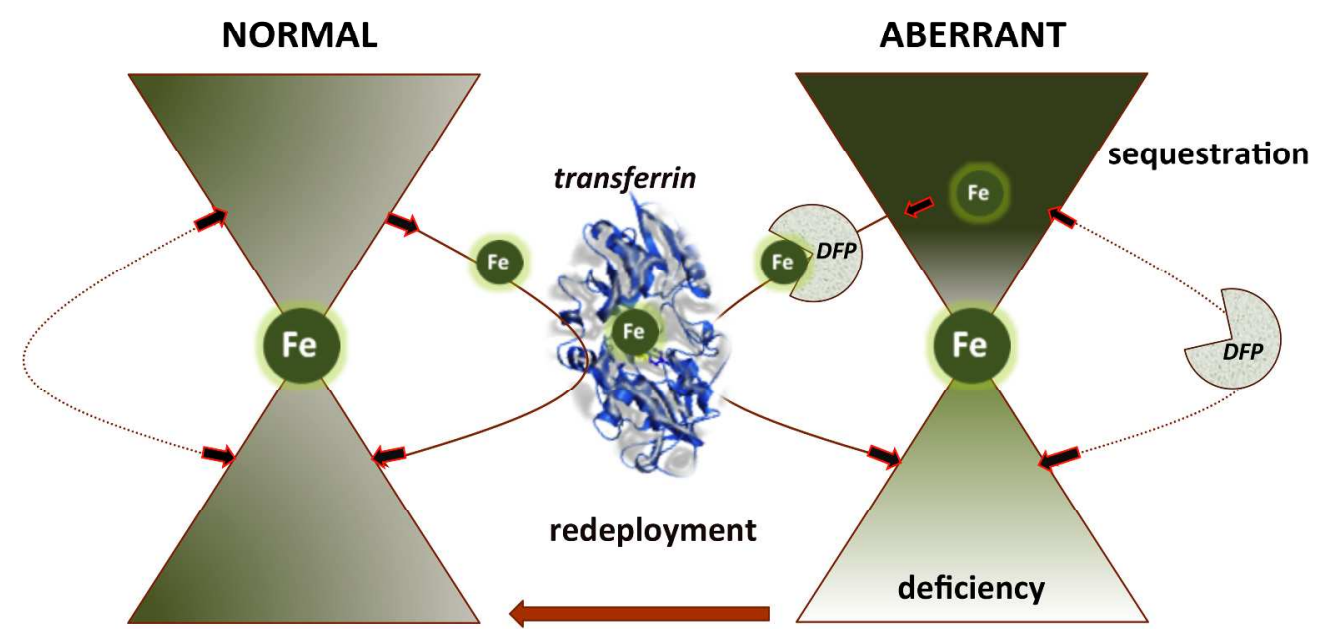

Figure 3

$252 \times 138 \mathrm{~mm}(300 \times 300$ DPI $)$ 
Table: Frequent asked questions, main findings and clinical implications

\begin{tabular}{|c|c|c|c|}
\hline $\begin{array}{l}\text { Frequent asked } \\
\text { questions }\end{array}$ & What is demonstrated? & Need to be demonstrated & Clinical implications \\
\hline $\begin{array}{l}\text { Iron overload in the } \\
\text { SNc? }\end{array}$ & $\begin{array}{l}\text { - First described in } 1924, \text { a similar period as Lewy bodies } \\
\text { - In models and patients brain analysis, }{ }^{9-21} \text { MRI and } \\
\text { ultrasounds } \\
\text { - Association with motor handicap }{ }^{9,12,13}\end{array}$ & $\begin{array}{l}\text { Biomarker for diagnosis and } \\
\text { prognosis? }\end{array}$ & $\begin{array}{l}\text { - Identification of iron overload: Hyperintensity of the dorsolateral } \\
\text { SNc by MRI (SWI) }{ }^{15} \text { and hyperechogenicity }{ }^{20,21} \\
\text { - Quantification of iron by MRI (R2*, QSM) }{ }^{9,12-19} \text { for follow up }{ }^{12,13}\end{array}$ \\
\hline $\begin{array}{l}\text { Why SNc is } \\
\text { vulnerable? }\end{array}$ & $\begin{array}{l}\text { - Naturally rich in iron }{ }^{1,2} \text { as required for dopamine (synthesis, } \\
\text { metabolism) })^{1,2,4} \text { and higher pace making activity in } \mathrm{SNc}> \\
\text { VTA }^{6} \\
\text { - Death by iron related to oxidative stress } \\
1,2,5-10,40,43\end{array}$ & $\begin{array}{l}\text { Cell types and factors involved } \\
\text { in the excess of oxidative stress } \\
\text { and iron redistribution? }\end{array}$ & $\begin{array}{l}\text { - High iron content render SNc vulnerable to oxidative stress } \\
\text { without adequate protective measures } 1,2,3,4,7-11 \\
\text { - Motor and non motor automatic activity requires high energy } \\
\text { demands }{ }^{6}\end{array}$ \\
\hline $\begin{array}{l}\text { What is the role of } \\
\text { neuromelanin? }\end{array}$ & $\begin{array}{l}\text { - Sequestration of harmful dopamine quinones (i.e. iron } \\
\text { related dopamine auto-oxidation). } \\
\text { - Neuromelanin lost in } \mathrm{PD}^{4} \text { frees 6-OHDA to impair } \\
\text { mitochondrial function. }\end{array}$ & $\begin{array}{l}\text { Cellular and brain mechanisms } \\
\text { of iron regulation? }\end{array}$ & $\begin{array}{l}\text { - Neuroprotection of neuromelanin by chelating metals (iron) and } \\
\text { xenobiotics? } \\
\text { - Neuromelanin measured with specific MRI sequence }\end{array}$ \\
\hline $\begin{array}{l}\text { Other brain regions } \\
\text { overloaded by iron? }\end{array}$ & $\begin{array}{l}\text { - Iron overload is complex, variable and dynamic in the other } \\
\text { regions } \\
\text { - The main other overloaded region is putamen } \\
\text { (identified by brain analysis and MRI) }\end{array}$ & $\begin{array}{l}\text { The status of the other regions } \\
\text { remains to be determined: } \\
\text { Nucleus caudatus, red nucleus } \\
\text { and globus pallidus, putamen? }\end{array}$ & $\begin{array}{l}\text { - Concept of progressive and extensive brain iron redistribution } \\
\text { - Specific correlations between regions, phenotypes and stages of } \\
\text { the disease to be determined }\end{array}$ \\
\hline $\begin{array}{l}\text { Are there different } \\
\text { types of iron? }\end{array}$ & $\begin{array}{l}-1 \% \text { of ferrous labile iron }\left(\mathrm{Fe}^{2+}\right) \text { required for normal } \\
\text { metabolism; harmful in excess (oxidative stress) } \\
-99 \% \text { of ferric iron }\left(\mathrm{Fe}^{3+}\right) \text { safely stored in equilibrium } \\
\end{array}$ & $\begin{array}{l}\text { In vivo measures of the labile } \\
\text { iron }\left(\mathrm{Fe}^{2+}\right) \text { available for } \\
\text { patients? }\end{array}$ & $\begin{array}{l}\text { - MRI is an indirect measure of ferric iron } \\
\text { - Iron-sensitive MRI evaluation depends on specific situations: } \\
\text { safely stored vs. pathological vs. non-active consequence }\end{array}$ \\
\hline $\begin{array}{l}\text { Is high dietary iron } \\
\text { exposure a risk factor } \\
\text { of PD? }\end{array}$ & $\begin{array}{l}\text { No demonstration but reported: } \\
\text { - In adult: no relation or weak association in males } \\
\text { - In early life: increase PD mortality rate in Western } \\
\text { countries? (Policy of iron fortified food). }\end{array}$ & Need prospective data & $\begin{array}{l}\text { - Iron overload of SNc is not a consequence of adult diet } \\
\text { - Policy (after the second world war) of systematic iron fortified } \\
\text { food could no longer be necessary or a worsening factor? (To } \\
\text { demonstrate) }\end{array}$ \\
\hline $\begin{array}{l}\text { Is there iron } \\
\text { deficiency in PD? }\end{array}$ & $\begin{array}{l}\text { No demonstration but reported: } \\
\text { - Association between low peripheral iron levels (anaemia, } \\
\text { low haemoglobin) and PD risk remains a matter of debate } \\
\text { - Requires meta-analytical confirmation }\end{array}$ & $\begin{array}{l}\text { - Need prospective data } \\
\text { - Mechanisms of abnormal iron } \\
\text { redistribution? }\end{array}$ & $\begin{array}{l}\text { - Abnormal regional iron redistribution; cellular, brain and body } \\
\text { overload and deficiency }^{2} \\
\text { - Care required in iron supplementation for anaemia in PD } \\
\text { (Efficiency? Risk?) }\end{array}$ \\
\hline $\begin{array}{l}\text { What is the } \\
\text { relationship between } \\
\text { iron and } \alpha \text {-synuclein? }\end{array}$ & $\begin{array}{l}\text { No demonstration but reported: } \\
\text { - Iron induces aggregation of } \alpha \text {-synuclein into intracellular } \\
\text { inclusions (i.e. Lewy bodies) }{ }^{28} \\
\text { - Pattern tightly concordant between brain iron deposit and } \alpha \text { - } \\
\text { synuclein pathology }{ }^{17}\end{array}$ & $\begin{array}{l}\text { Pivotal interplay between iron, } \\
\text { dopamine and } \alpha \text {-synuclein } \\
\text { pathology to influence } \\
\text { dopaminergic neurotransmission } \\
\text { and disease progression? }\end{array}$ & -Therapeutic targets for neuroprotection and dopasensibility? \\
\hline
\end{tabular}


- $\alpha$-Synuclein pathology involved in iron homeostasis ${ }^{28}$ and reduced by iron chelation ${ }^{29,30}$

\begin{tabular}{|c|c|c|c|}
\hline $\begin{array}{l}\text { What is the } \\
\text { therapeutic concept of } \\
\text { "conservative" iron } \\
\text { chelation }\end{array}$ & $\begin{array}{l}\text { - Neuroprotection in PD models by iron chelation } \\
\text { - Dopaminergic neuronal death by iron deficiency } \\
\text { - Concept: low dose of deferiprone redeploys captured iron to } \\
\text { extracellular apo-transferrin, and subsequent distribution } \\
\text { avoids iron deficit: preclinical efficacy and clinical safety } \\
\end{array}$ & $\begin{array}{l}\text { Efficacy to be confirmed with } \\
\text { large trial in progress? } \\
\text { (FAIRPARK-II) } \\
\text { - Trials also in progress for } \\
\text { PKAN-2, ALS, AD? }\end{array}$ & $\begin{array}{l}\text { Careful therapeutic iron redistribution by conservative chelation } \\
\text { based on iron scavenging and redeployment (Fig. 3) may afford } \\
\text { neuroprotection without anaemia (risk of reversible neutropenia in } \\
1-3 \%)\end{array}$ \\
\hline $\begin{array}{l}\text { Are there several } \\
\text { types of cell deaths in } \\
\text { PD? }\end{array}$ & $\begin{array}{l}\text { - Apoptosis (mainly with oncogenic cell line): negative trials } \\
\text { - Mitophagy in models and genetic causes (Pink-1, Parkin,..) } \\
\text { - Ferroptosis in models }{ }^{31-33} \text { (Fig.2) }\end{array}$ & $\begin{array}{l}\text { - Mitophagic modulator } \\
\text { - Antiferroptotic drug (both iron } \\
\text { chelators and specific inhibitors) }\end{array}$ & New upcoming therapeutic targets for a combined therapy? \\
\hline $\begin{array}{l}\text { IN TOTAL: Is iron } \\
\text { the cause of PD? }\end{array}$ & $\begin{array}{l}\text { NO but a worsening factor if present 1) in excess and 2) } \\
\text { associated with PD physiopathology }\end{array}$ & $\begin{array}{l}\text { The interplay between iron } \\
\text { and the pathological causes } \\
\text { (e.g. synucleinopathy, } \\
\text { mitochondriopathy): "double } \\
\text { hit theory"? }\end{array}$ & $\begin{array}{l}\text { - In specific situations iron overload could be a marker of } \\
\text { degeneration and a risk factor for degeneration } \text { 1,2,7-21,31-37 } \\
\text { - A therapeutic strategy? } 9,36,37\end{array}$ \\
\hline
\end{tabular}

